\title{
História do Grupo Escolar Elizeu Campos de Mirandiba (Pernambuco)
}

History of the Elizeu Campos School Mirandiba (Pernambuco)

Historia de la Escuela Elizeu Campos de Mirandiba (Pernambuco)

\author{
José Luís Simões \\ Universidade Federal de Pernambuco (Brasil) \\ http://lattes.cnpq.br/1520982273735802 \\ https://orcid.org/0000-0003-4915-2323 \\ joseluis2711@yahoo.com.br \\ Tulane Silva de Souza Pedrosa \\ Universidade Federal de Pernambuco (Brasil) \\ http://lattes.cnpq.br/6610402830010113 \\ https://orcid.org/0000-0002-9095-1998 \\ tulanesouza@live.com
}

\section{Resumo}

O presente artigo é efeito da nossa dissertação de mestrado, que teve como um de seus objetivos historiar a gênese da educação pública na cidade de Mirandiba, localizada no sertão pernambucano. O Grupo Escolar Elizeu Campos foi inaugurado em 1934 e demolido em 1990, teve como aportes pedagógicos a tradicional cartilha e o método intuitivo, atrelados a rigidez proveniente do civismo e patriotismo, características dos grupos escolares em âmbito nacional. O Grupo Escolar Elizeu Campos institui-se por esforço do Coronel Elizeu Campos, personagem que também fundou a cidade juntamente com os quilombolas, índios e famílias andarilhas do pós-cangaço. Os entraves políticos que levaram a construção e demolição da instituição escolar foi a questão com a qual problematizamos este estudo, nos levando a exalunos, professores e literaturas que pudessem responder e reconstruir a história da educação em Mirandiba, e da primeira escola pública do local.

Palavras-chave: Grupo Escolar. História da Educação. Mirandiba. Pernambuco. 


\begin{abstract}
This article shall effect of our dissertation, which had as one of its objectives historicize the genesis of public education in the city of Mirandiba, located in the pernambucan hinterland. The Elizeu Campos School opened in 1934 and demolished in 1990, was teaching the traditional contributions primer and the intuitive method, coupled stiffness from the civics and patriotism, characteristics of school groups nationwide. The Elizeu Campos school establishing itself by effort of Colonel Elizeu Fields, a character who also founded the town along with the Maroons, Indians and outsiders. The political barriers that led to the demolition of the school institution, was the question with which we problematize this study, taking us to former students, teachers and literature that could respond and reconstruct the history of education in Mirandiba, and the first public school site.
\end{abstract}

Keywords: School. History of Education. Mirandiba. Pernambuco.

\title{
Resumen
}

Este artículo se procederá de la tesis doctoral, que tenía como uno de sus objetivos historizar la génesis de la educación pública en la ciudad de Mirandiba, situado en el interior de Pernambuco. La escuela abrió sus puertas en 1934 campos Chander y demolido en 1990, fue enseñar la cartilla de contribución tradicional y el método intuitivo, rigidez acoplado de civismo y patriotismo, características de grupos de escolares en todo el país. La escuela grupo Elizeu Fields estableciéndose por esfuerzo de coronel Elizeu Fields, un personaje que también fundó la ciudad junto con los cimarrones, indios y extranjeros. Las barreras políticas que llevaron a la demolición de la institución escolar, fue la pregunta con la cual nos problematizar este estudio, nos lleva a ex alumnos, profesores y literatura que pudiera responder y reconstruir la historia de la educación en Mirandiba y la primera escuela pública sitio.

Palabras clave: Escuela. Historia de la Educación. Mirandiba. Pernambuco. 


\section{A cultura escolar nos grupos escolares brasileiros: o que diz a historiografia.}

Este artigo é resultado de um estudo que compreendeu pesquisar a história da institucionalização a demolição do Grupo Escolar Elizeu Campos de Mirandiba, cidade do sertão pernambucano. A inauguração deste aconteceu na década de 1930 e foi a primeira escola pública da cidade, sendo demolido em 1990. Saviani (2007) sugere que "propor-se a reconstruir historicamente as instituições escolares brasileiras implica admitir a existência dessas instituições que, pelo seu caráter durável, têm uma história que nós não apenas queremos como necessitamos conhecer" (p.24). O cenário político e cultural que recebeu a instituição situava-se no período chamado coronelista em Mirandiba, que para Leal (2012) tem uma característica variada dado o recorte temporal.

[...] concebemos o "coronelismo" como resultado da superposição de formas desenvolvidas do regime representativo a uma estrutura econômica e social inadequada. Não é, pois, mera sobrevivência do poder privado, cuja hipertrofia constituiu fenômeno típico de nossa história colonial. É antes uma forma peculiar de manifestação do poder privado[...] (LEAL, 2012, p.23)

No tocante, e entendendo que a cultura escolar advém de um estilo governamental, e não é um fato histórico dado, sendo ela capaz de abrigar várias definições, mapeamos o sentido de cultura escolar para diversos autores para adentrar na cultura escolar de Mirandiba. Procuramos estudos que tratassem com mais ênfase a institucionalização escolar em suas formas culturais, e encontramos em Saviani (2007) um conjunto de saberes acerca da cultura institucional das escolas em âmbito nacional.

Sendo o Grupo Escolar Elizeu Campos uma instituição advinda do sertão, sobretudo de um distrito rural, consideramos importante citar o que dizem alguns autores sobre a implementação de grupos escolares nas zonas rurais brasileiras. Podemos citar Sizenando Costa como um dos principais autores sobre o tema, sendo fonte para diversos pesquisadores da temática escola rural. Ele escreveu em 1941 o livro "A Escola Rural”, onde trata da implementação das escolas rurais como fator econômico e social.

Podemos citar ainda Pinheiro ${ }^{1}$ que discute sobre escolas rurais na Paraíba, entre 1935 e 1960, que utilizou como fonte de investigação as mensagens dos presidentes da República para o congresso nacional assim como relatórios sobre as instituições, suas peculiaridades e discursos em volta das mesmas, gerando um vasto conteúdo sobre a escolaridade rural no Brasil.

Saviani (2007) pontua a origem da escola a partir do poder de uma classe dominante sobre outra dominada, determinando e diferenciando o que cada classe teria por educação institucional. "A educação dos membros da classe que dispõe de ócio, de lazer de tempo livre passa a se organizar na forma escolar, contrapondo-se à educação da maioria que continua a coincidir com o processo de trabalho" (p.9). O referido autor tratou da institucionalização escolar por dois pontos de vistas, o modo empírico e "pela via da síntese", onde o primeiro se destina a classe dominante, e o segundo para a classe dominada.

Castanho (2007) entende a cultura escolar como "fenômeno da institucionalização da educação e também como centralidade escolar no âmbito cultural, isto é, nas consequências culturais da escola, [que] firmou-se decisivamente no país. E isso, como vimos, em todos os níveis e modalidades da educação" (p.51).

\footnotetext{
${ }^{1}$ Disponível em: http://www.histedbr.fe.unicamp.br/acer_histedbr/seminario/. Acesso em 14 ago. 2018
} 
Sanfelice (2007) aborda a cultura por questões identitárias ímpares afirmando que "as relações da população com as instituições escolares geram situações não previstas e que alteram, localmente, planos oficiais ou diretrizes de uma política educacional. Há, portanto, sempre uma identidade" (p.79). Ele acrescenta dizendo que cabe ao historiador buscar entender qual identidade o local estudado revela.

Nesse sentido, e ainda abordando aspectos do que vem a ser cultura educacional institucionalizada encontramos em Araújo (2007) uma compreensão "no campo das intencionalidades que conformam as atividades educativas; [onde] cabe compreender que a denominada cultura escolar - é, dialeticamente, um afluente bem como um defluente, da própria cultura e não apenas um manancial de onde jorra uma cultura" (p.95).O trabalho do pesquisador é buscar a fonte cultural, desbravá-la e entende-la.

Foi o que fez Monarcha (2007) o autor destaca que "ao longo de 1930 e 1940 [surgi] uma conjunção de fatores [que] favoreceram sobremaneira o surgimento de uma consciência duplamente sociológica e histórica do passado cultural e educacional do país" (p.129), o que incutiu na atmosfera cultural educacional uma necessidade de comunicação e de transmissão desta cultura.

Esta transmissão da cultura educacional e escolar deu-se principalmente pelo caráter modernizador observado nas instituições de ensino, e nos grupos escolares mais fortemente, já que a arquitetura dos mesmos é objeto de estudos de Norte a Sul do Brasil. Buffa (2007) analisa o fato de todo espaço ser passível de ensino, uma vez que o âmbito educacional é todo aquele onde acontece uma aprendizagem. No entanto, ressalta que "uma escola é muito mais que isso, e o edifício escolar, pode facilitar ou dificultar a aprendizagem, a convivência, [e] o desenvolvimento dos alunos. Em suma, os espaços educam. [E] ninguém confunde conseguir comunicar-se com o conhecimento de uma língua" (p.157).

Assim como a arquitetura das instituições escolares não é objeto de estudo apenas de arquitetos, a historiografia pode ser metodologia utilizada por pesquisadores de diversas áreas, para além de historiadores.

Noronha (2007) fez o debate metodológico acerca da escrita da história a respeito das instituições escolares. A autora sintetiza uma crítica frente as lacunas deixadas pela história tradicional, ensejando uma investigação através do que ainda não foi perguntado, $\operatorname{logo}$, não respondido.

Tal anseio gerou a necessidade de uma crítica e reconstrução através dos estudos gerados em revistas científicas, uma vez que tais referências são pouco analisadas. Mas, ainda em torno da cultura educacional observamos a preocupação em entender a cultura brasileira imbricada com as culturas dos imigrantes no Brasil.

A imigração ocorreu para fortalecimento econômico no País, no entanto, a cultura educacional brasileira não abarcava todo território nacional, deixando brecha para forças opostas frente a educação homogênea. Luporini (2007) trouxe luz à investigação sobre alternativas de se pensar em identidade cultural educacional.

Os modos tratados pela autora supracitada giram em torno das "experiências históricas comuns e códigos culturais compartilhados que fornecem quadros de referência e sentido, [e] pontos críticos de diferença profunda - rupturas e descontinuidades que constituem as singularidades dos diferentes grupos sociais" (LUPORINI, 2007. p. 210).

As similaridades e disparidades culturais juntamente com a transição política, fez da educação brasileira palco para disputas, onde o cenário político era e ainda é o principal alvo a ser alcançado, uma vez que a gestão é o auge do controle social na hierarquia republicana positivista.

\section{O Grupo Escolar Elizeu Campos: reerguendo suas paredes}

Para reerguer as paredes da história do Grupo Escolar Elizeu campos realizamos entrevistas com ex-alunos, ex-funcionários, e análises de documentos pessoais dos mesmos, 
uma vez não há registros da existência da instituição nas gerências e secretarias de educação da cidade e de municípios circunvizinhos.

Segundo dona Neném de Talí, primeira merendeira do grupo escolar, 1934 foi o ano de inauguração do Grupo Escolar Elizeu Campos, sua construção e adequação se deu através de negociações entre Capitão Elizeu com o Deputado Agamenon Magalhães, no entanto, não há registros no Diário Oficial da União que confirmem a existência do grupo.

No processo de captação documental para esta pesquisa, foi revelado um fator interessante e de certo modo preocupante diante da importância dada aos documentos dos grupos escolares do Sertão. Fato é que em nenhuma das instituições públicas procuradas havia documentos que provassem a existência do Grupo Escolar Elizeu Campos.

Sem muitas pistas de sua existência, seja na forma de portaria de transferência institucional ou de mudança de nomenclatura, como ocorreu com outras instituições, ficou subentendido que o Grupo Escolar Elizeu Campos na realidade nunca existiu na forma da lei, como se sua institucionalização fosse clandestina e arbitrária.

Não fosse o boletim de um ex-aluno, o relato da ex-professora Valquíria Gomes Vieira e dos ex-alunos João Batista Rodrigues dos Santos - conhecido como Pitel e Nelson Pereira de Carvalho, não seria possível historicizar as práticas pedagógicas da primeira instituição pública de ensino de Mirandiba.

Sabendo que o Grupo Escolar Elizeu Campos transferiu suas atividades para a Escola Estadual Francisco Pires, por volta da década de 1970, procuramos na Gerência Regional de Educação do Sertão Central - G.R.E, no setor de planejamento mais especificamente, algum registro dessa transferência.

O setor de planejamento da G. R. E do Sertão Central possui documentação de muitos grupos escolares, mas não possui nenhuma documentação que leve o nome do Grupo Escolar Elizeu Campos. Inclusive detém documentos que descrevem a Escola Estadual Francisco Pires como a primeira instituição pública de ensino em Mirandiba.

Em visita a Escola Francisco Pires fomos informados que toda documentação antiga que existia no arquivo da escola havia sido incinerada em gestões anteriores. O motivo dado para a prática foi justificado como de praxe, pois, o arquivo da instituição é pequeno e não suporta toda documentação relativa à alfabetização dos mirandibenses.

Este artigo é, portanto, documento que agrupa informações sobre a gênese da educação dos mirandibenses. Lembrando que outros pesquisadores já investigaram as práticas sociais da cidade pelos olhares biológicos (CÓRDULA, 2008), geográficos (PAOLIELLO, 2010) e etnográficos (FAURE, 2015), enriquecendo o arcabouço teórico deste estudo.

Figura 1 - O Grupo Escolar Elizeu Campos em 1960

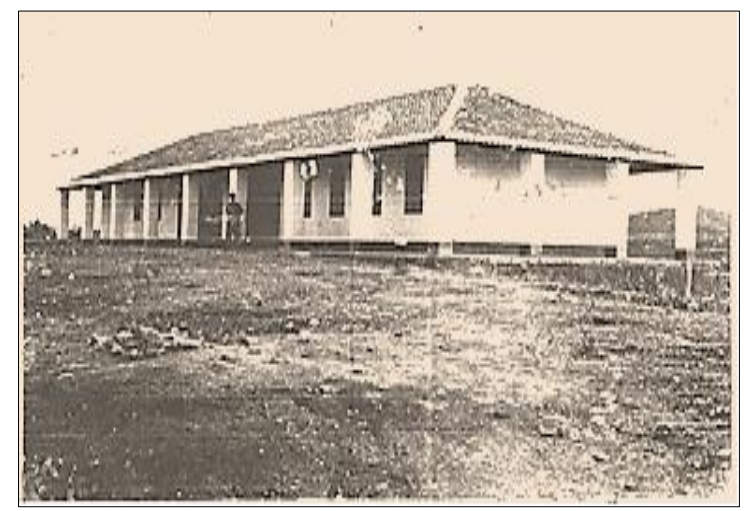

Fonte: Mabel Solange Bezerra de Carvalho. Ex professora egressa 
A imagem anterior, adquirida por uma doação em conversa informal com Mabel Solange, é uma fotografia da década de 1960, o local onde funcionava o grupo, ficava em cima de uma colina de onde se avistava todo centro de Mirandiba. Nos arredores da instituição havia uma horta e um poço.

Tanto a horta quanto o poço eram cuidados pelos alunos e pela merendeira do grupo, mas não eram todos que praticavam essas tarefas. A seleção era feita de acordo com a dedicação do aluno nos assuntos de sala de aula, como lembra a ex-professora Valquíria. "Todas as professoras reclamavam porque não conseguiam deixar a sala homogênea, mas eu conseguia, todo aluno meu aprendia igual, os que não aprendiam na sala, aprendiam na horta, enchendo o poço, mas aprendia" (VALQUÍRIA, 2016).

Os métodos pedagógicos, segundo a ex-professora, se baseavam na intuição, na descoberta do novo, mas na prática se fazia necessário dar importância ao trabalho do aluno, a exemplo temos a tese de Porcel (2006) que valoriza o papel que o trabalho tem na infância. Ela lembra que cada aluno tinha seu papel em sala, as funções eram de inspetor, apagador de lousa, zelador, abastecedor do pote d'água, entre outras tarefas extraclasse, como cuidar do quintal, pegar água no poço e cuidar da horta

Nesse método, não se inclui castigos, segundo os três entrevistados, sendo dois exalunos e uma ex-professora, em suas memórias não havia lembranças da aplicação de castigos em qualquer aluno, no entanto a palavra rigidez aparece no método de ensino quando a pergunta feita foi: Como era o dia a dia do grupo escolar? A resposta foi a mesma: "Rígido!" A rigidez a que se referiam os entrevistados estava ligada a disciplina exigida em sala.

Segundo Vilela (2000) o símbolo pedagógico primário dos grupos escolares no Brasil girava em torno de uma rigidez militarista. Os moradores de Mirandiba e alunos do Grupo Escolar Elizeu Campos acompanhavam o método militar, mas não adquiriram algumas ferramentas modernizadoras que acompanhavam o militarismo nas escolas, como a imprensa, por exemplo, utilizada por outros grupos escolares.

A falta do acesso à comunicação impressa ou radiofônica, ilhou o mirandibense e suas chances de aquisição de alguns conhecimentos, sendo assim o Grupo Escolar Elizeu Campos, era responsável não só pela educação primária dos munícipes, como também, principal canal de informações para os munícipes. O papel da imprensa na circulação dos ideais civilizadores e o não acesso a mesma afirma a incompletude do projeto republicano na instalação do Grupo Escolar Elizeu Campos em Mirandiba.

Essa falta da circulação das informações e o não acesso a comunicação, juntamente com a rigidez militar, tornou a educação dos mirandibenses desnecessária para o bom convívio interpessoal, e por consequência não estimulou todo cidadão a obter os conhecimentos escolares. Sendo algo necessário para aqueles que poderiam sair da cidade, onde o conhecimento escolar era de extrema importância para sobrevivência. Esse ponto de vista tendencioso, voltado para o que seria o problema número um do Grupo Escolar Elizeu Campos se baseia no fato de que a falta de comunicação e informação é um problema em qualquer comunidade.

No campo da cultura, mais propriamente a cultura rural, a educação válida para o bom convívio com a comunidade está ligada ao seu ofício diário. O saber cultivar e administrar a cultura de subsistência é primordial para vida rural. Esse saber esteve ligado ao Grupo Escolar Elizeu Campos, como válvula de escape para os exercícios em sala de aula. Foi observado através das entrevistas realizadas que o castigo e o prêmio ao aluno estavam ligados a sua representação em sala, papel que cada um era obrigado a desempenhar. De inspetoria a carregar água do poço, cada um teria que se encontrar naquele caminho.

Saber seu lugar e desempenhar seu papel é questão do campo identitário do sujeito como símbolo, a fenomenologia da educação tenta explicar por uma dimensão compreensiva 
da manifestação humana, que o sujeito símbolo se traduz na dialética do tópico e utópico (REZENDE, 1990).

Figura 2 - Professoras de Mirandiba na década de 1970.

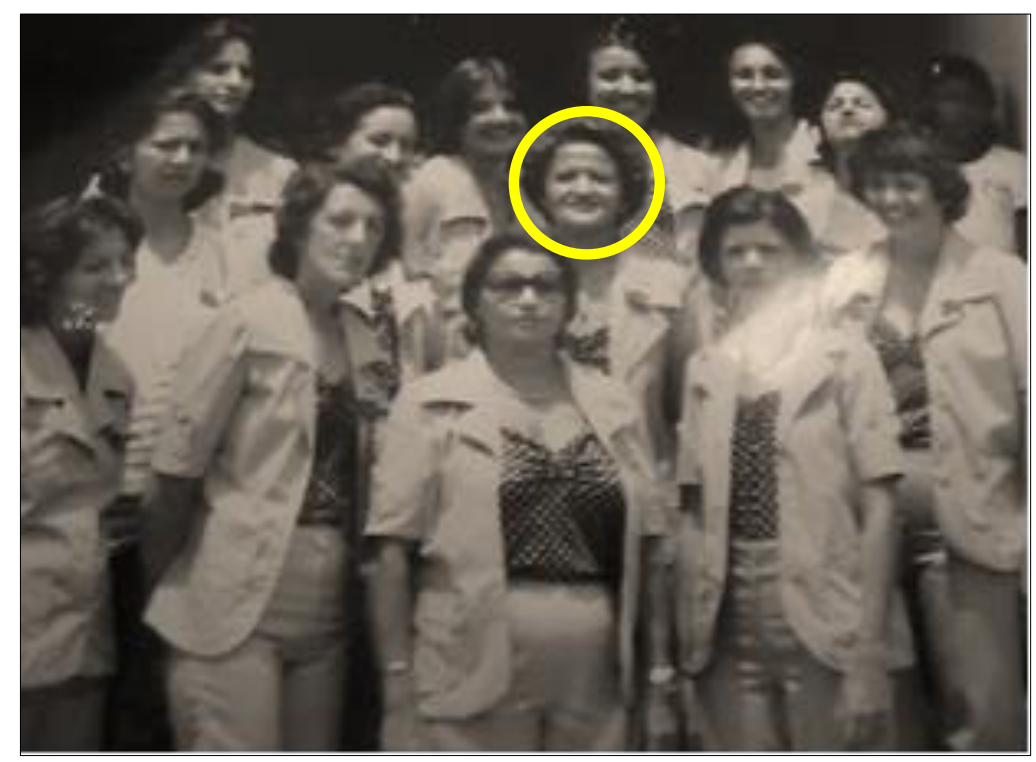

Fonte: Arquivo do EREM Francisco Pires.

$\mathrm{Na}$ foto consta representação de parte das professoras do município de Mirandiba, no qual a professora Valquíria fez parte (em destaque). Nota-se a utilização de uniformes e padronização inclusive do visual das professoras, ressaltando a iniciativa de padronização existentes nos grupos escolares.

A movimentação das professoras na década de 1970 em Mirandiba envolvia outra instituição de ensino, o Grupo Escolar Francisco Pires, fundado em 1969 por intermédio do prefeito na época, Francisco Alves de Carvalho Nunes, o conhecido Chico do Arroz. O novo grupo escolar recebeu o nome em homenagem ao pai do então prefeito.

Com a nova instituição em funcionamento, com as características de escola urbana e moderna que se propunha os grupos escolares republicanos (SAVIANI, 2007), as professoras e professores da cidade passaram a almejar fazer parte do estilo renovado ao qual se apresentou o Grupo Escolar Francisco Pires.

Em 1970, os professores e alunos da cidade decidiram por abandonar o Grupo Escolar Elizeu Campos, elencando o Grupo Escolar Francisco Pires como referência da educação pública de Mirandiba. Característica legitimada pelo plano pedagógico e político da cidade que elevou o grupo escolar à Escola de Referência em Ensino Médio Francisco Pires, em funcionamento até a atualidade.

A historiografia a respeito de grupos escolares que não receberam o projeto republicano em sua completude (indústria, educação e imprensa) está no campo dos grupos escolares rurais. Estas instituições são lembradas na historiografia como instrumento de auxílio aos imigrantes, que enfrentaram diversas dificuldades, desde a arquitetura à defasagem do alunado.

A difusão do ensino primário nas zonas rurais enfrentou diversos problemas de natureza pedagógica e administrativa, como a falta de provimento de professores para as escolas criadas, a precariedade dos locais de funcionamento das escolas, as condições de organização das escolas isoladas, a baixa frequência dos alunos e o abandono escolar, devido ao trabalho nas lavouras (SOUZA, R. F., 2014. p. 15). 
Entendendo as peculiaridades ou problemas inerentes aos grupos escolares rurais como pontua Souza, R. F. (2014), fica nítida a incompletude do projeto republicano em alguns grupos. Sendo correto afirmar que os problemas da instituição dos grupos escolares se apresentaram de diferentes maneiras a depender do contexto que se instalaram.

O método pedagógico das exigências republicanas também não era seguido à risca, já que os problemas educacionais estão nas mais variadas esferas da cultura escolar. Diante disto surge a busca por entender o método pedagógico praticado no Grupo Escolar Elizeu Campos e suas disparidades.

\section{Personagens do Grupo escolar Elizeu Campos}

A educação em série e as divisões de tarefas como prêmio ou punição fizeram parte da hominização ou humanização dos alunos do Grupo Escolar Elizeu Campos? Rezende (1990) defende que a humanização se inicia através da aprendizagem historicamente possível. Imbricando "o início da humanização, da história, da cultura e da aprendizagem" (p. 47), como partes de um bloco agrupado e indivisível.

Levando-se em conta que a aprendizagem não está apenas entre os muros das escolas, outra pergunta se levanta: como a falta de comunicação e informação entre integrantes de uma comunidade e com o mundo exterior, afeta na qualidade de vida? Concordamos com Rezende:

É verdade que o homem pode ser adestrado, amestrado, treinado, domesticado. Mas isto não é aprendizagem, ou, ao menos, não é aprendizagem humana. Ao contrário, tanto psicológica como sociologicamente, quando isto acontece assistimos a um processo de regressão, como fator de desumanização e alienação (REZENDE, 1990. p.48).

Não afirmando que os métodos positivistas do ensino são retrógrados, mas, afirmando que algumas metodologias pedagógicas não são humanizadas buscamos nas memórias que revelassem qual representação simbólica o método de ensino do grupo escolar teve na formação humana dos mirandibenses.

A escolha dos ex-alunos se justifica por alguns aspectos, Nelson Pereira de Carvalho e João Batista Rodrigues dos Santos (ou Pitel), afirmam ter estudado na mesma época entre 1960 e 1969, ambos não sabem ao certo quantos anos passaram na instituição, sabem que terminaram o primário no Grupo Escolar Elizeu Campos e estudaram com a então professora Valquíria.

A ex-professora e os ex-alunos selecionados também não guardaram documentos do grupo, diferente do que ocorreu com o Grupo Escolar Francisco Pires que tem boa parte de suas memórias expostas em um plano pedagógico facilmente encontrado na internet.

A influência sofrida no Grupo Escolar Elizeu Campos foi para o ex-aluno Nelson Pereira de Carvalho muito positiva, ele revelou: - "aprendi a ser organizado e pontual, manter as unhas curtas e limpas. Sempre que algum aluno não respondia as tarefas corretamente era convidado a trabalhar na horta na hora do recreio".

Levando-se ao entendimento a respeito da metodologia da professora Valquíria, ela não recorda as particularidades dos alunos, mas seus ex-alunos lembram de sua rigidez metodológica, que os estimulava a sempre responder tudo corretamente.

João Batista Rodrigues dos Santos, o Pitel, 62 anos, fez parte deste recorte intercultural ambivalente entre urbano e rural. Não se recorda de ter feito trabalhos manuais como castigo. "Assim que cheguei na primeira série, eu passei pouco tempo, alguns meses só, antes de terminar o ano eu fui adiantado para o terceiro ano só tinha eu e mais dois alunos, quando acabou os estudos do grupo eu passei no teste para o ginásio e fui estudar fora” (PITEL, 2016). 
Nelson Pereira, 60 anos, dentista, já foi prefeito da cidade e deputado estadual, e se lembra do amigo Pitel: - "ele era mais adiantado que eu, me lembro do coleguismo, aquele ar de liberdade, uma escola modernizada, a merenda era ótima feita por dona Neném, escola dura, rígida, a diretora era dona Lilia, da casa grande" (NELSON, 2016).

Além das merendas, Nelson lembra, ainda, que o local era de alegria, "os momentos com os meus colegas Antônio Torres, Assis, que também são ex-prefeitos daqui, era maravilhoso aprender com dona Valquíria, todo mundo passou pelo grupo. E aí foi feita a derrubada para construção do fórum, de repente, parecendo uma falta de zelo pelo patrimônio, pela história do município" (NELSON, 2016).

Pitel também demonstrou pesar ao se lembrar do Grupo Escolar Elizeu Campos. "Gostei muito daquela escola, inclusive fiquei triste quando voltei à cidade uns 20 anos depois tinham demolido tudo. Muito triste mesmo". Após afirmar que sentia muito pelo fim do Grupo Escolar Elizeu campos, Pitel pausou a fala cabisbaixo.

Como outro grupo escolar se instituiu na cidade e devido ao fato de que, tradicionalmente, os prefeitos não dão continuidade aos trabalhos dos antigos gestores em Mirandiba (SOUZA, T., 2013), ficou claro que apesar da gestão da cidade ser feita por integrantes da mesma família até os dias atuais, não significa que são unidos pelo mesmo propósito social.

Dentro do âmbito educacional, as políticas de convivência eram impostas pela autoridade, assim como nas relações entre os munícipes. Nelson lembra de alguns castigos como forma de imposição. "O ensino era rígido, com o rigor da palmatória ainda, mas muitas escolas eram assim. Peguei o finzinho dos castigos, não me lembro de prêmios, mas também eu não tirava boas notas" (NELSON, 2016).

Após esta declaração Nelson ri bastante. Seu amigo Pitel, quando perguntado sobre a imposição e castigos, não se recorda de tal atitude para com ele, mas ressalta que alguns trabalhos manuais realizados por ele, como carpintaria, eram para construir coisas em seu benefício, como carrinhos e caminhões de madeira. Na opinião de Pitel, o Grupo Escolar Elizeu Campos representou algo sublime e esplêndido.

Era maravilhoso, português, matemática, geografia e ciências, tinha o desfile cívico e era muito rígida a direção da escola e tudo, mas eu participava dos desfiles cívicos, fazia parte da banda marcial tocando o bombo, eu e meus dois colegas de classe fazíamos trabalho tipo artesanato, carrinhos, barcos, trabalho de carpintaria, tudo pra gente mesmo, alunos como eu eram sempre minoria (PITEL, 2016).

Assim como Nelson, Pitel se recorda das festas realizadas no grupo, "dia das mães era comemorado, Sete de Setembro, o grito do Ipiranga, era tudo bem comemorado e muito bonito" (PITEL, 2016). Aumentando o som da voz e exaltando o grupo, Pitel demonstra orgulho em ter estudado no grupo, mas não recorda da sua participação na formatura. Nem tem fotos ou registros que comprovem sua fala de estudante exemplo.

Novamente cabisbaixo e diminuindo o tom de voz, Pitel recorda e quase sussurrando diz: - todo morador daqui com a minha idade mais ou menos e que aprendeu alguma coisa, aprendeu no Grupo Escolar Elizeu Campos e acabaram com tudo, não deixaram nenhum arquivo, nada, nada, nada." Ele continua, "a gente recebia os boletins e tudo, mas tinha que deixar na secretaria, essa escola existiu. As tarefas, a gente tirava dos livros e decorava tudo, tinha que dizer tudo que aprendeu" (PITEL, 2016).

As lições das coisas ministradas por dona Valquíria eram repassadas em casa, Nelson e Pitel contavam com ajuda das mães para decorar tudo, como Pitel mesmo lembra: "Minha mãe e meu pai eram da roça mas sabiam um pouquinho e me ajudavam nas lições de casa. Eu me destaquei mesmo em matemática e por isso passei direto para o terceiro ano" (PITEL, 2016). 
Integrante de uma classe com apenas três alunos e morando nas Posses, fazenda distante 12 quilômetros do Grupo Escolar Elizeu Campos, Pitel não se recorda de ter faltado as aulas, diferente de Nelson que viajava sempre com seu pai. Aliás, a assiduidade e participação nas festividades era obrigação do aluno, ao que consta portaria $n^{\circ}$. 708, de 27 de dezembro de 1943 do Ministério da Agricultura.

Pitel recorda ainda que naquela época era muito difícil sair do primário e ir para o Ginásio, e quem concluía o primário era muito respeitado, porque segundo ele, "já era muita coisa". Para fazer faculdade era muito difícil, quase impossível e ele concluiu o ginásio trabalhando na Chesf em Paulo Afonso (BA).

Nas memórias dos ex-alunos e ex-professora não aparecem a figura do inspetor ou de médicos no quadro de funcionários, não acompanhando o que diz a historiografia atualizada e tradicional sobre o importante papel desses profissionais para completude da proposta educacional dos grupos escolares no Brasil.

A imponência dos grupos descrita como fator condicionante da moderna arquitetura das instituições também não aparece nas memórias aqui analisadas, a estrutura adaptada ao contexto de Mirandiba deixa claro o esforço em acompanhar as tradições do Sudeste de forma mutável e intercultural.

As diferenças estabelecidas pelo contexto político, histórico, geográfico e cultural estão também nos caminhos seguidos pelos ex-alunos. Nelson, após terminar o primário no Grupo Escolar Elizeu Campos, fez o ginásio em Recife e a primeira graduação em Minas Gerais. Voltou a Mirandiba e entrou no jogo político da cidade na década de 1990.

Pitel retornou a cidade em 1980, empregado da Chesf, entrou no jogo político da cidade só quando Nelson foi prefeito, em 1990, sendo o primeiro gestor a convidar negros para administração pública municipal. Atualmente, Pitel é funcionário em cargo comissionado na prefeitura de Mirandiba, lotado na Gerência de Patrimônio Histórico.

Figuras 3/4 - Nelson Pereira de Carvalho à esquerda e João Batista Rodrigues dos Santos - Pitel
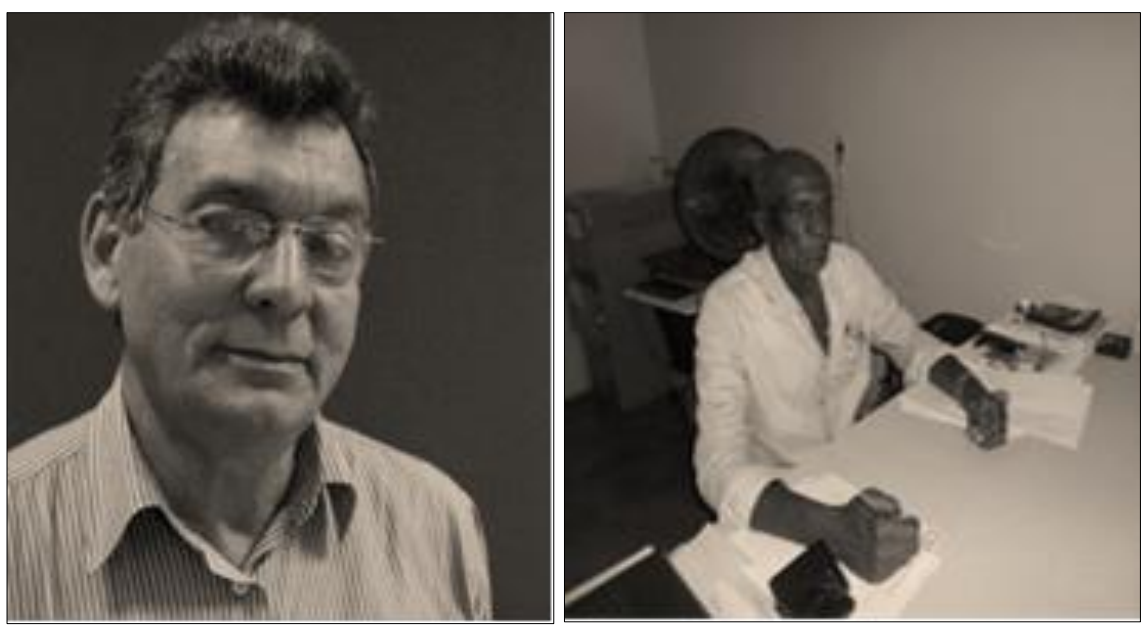

Fontes: Respectivamente, foto retirada da internet e foto feita pela pesquisadora

Com Nelson Pereira, a entrevista foi realizada em seu consultório onde exerce a função de dentista, o encontro foi por acaso, nada combinado previamente. Ele foi solícito e cordial em ceder suas memórias. Com João Batista (Pitel) a entrevista foi previamente marcada e realizada em seu local de trabalho na prefeitura, suas memórias expostas com mais detalhes inclinou a pesquisa para uma atmosfera descolonial dos saberes (PETERS, SCHNORR \& TAUSCHECK, 2014). 
As perguntas feitas aos ex-alunos foram as mesmas, quais são as memórias mais alegres e mais tristes, o que aprenderam, como aprenderam, o que faziam no recreio, quais atividades extraclasse realizavam, como eram tratados, quem eram seus colegas, o que achavam de mais moderno, como era a inspeção, higienização e relação com a professora. Ficou pendente o assunto higienização, pois segundo os ex-alunos e ex-professora não se trabalhou esse tema.

Diferente da instalação de outros grupos escolares em Pernambuco, as medidas higienistas não foram encontradas nas matrículas ou na inspeção anual do Grupo Escolar Elizeu Campos. Mas se entendermos a higienização como medicina do social que se deu em consequência da relação entre brasileiros e estrangeiros não é estranho que não tenha ocorrido em Mirandiba, pois o município mesmo com a instalação de indústrias não recebeu imigrantes para mão de obra, e sim os cabras e quilombolas.

Mesmo tendo a mesma nacionalidade quilombolas, cabras e brancos, não tinham relacionamentos ou contatos físicos em Mirandiba, esta aproximação se deu de fato após mandato de Nelson Pereira na década de 1990 (FAURE,2015). Portanto, não se fizeram necessárias as medidas higienistas. Não por se tratar de um contexto rural, mas por Mirandiba ter características separatistas. $\mathrm{O}$ que direciona a pesquisa para um aspecto educacional mais profundo.

A ordem e o progresso como princípios Republicanos, juntamente com o cunho cívico patriótico e midiático repassado aos alunos dos grupos escolares fizeram do projeto educacional, exemplo de unidade e força nacional que se preparava para urbanização e modernização do local onde se instalava.

No entanto, a cidade de Mirandiba quando recebeu a primeira instituição pública de ensino, baseava-se no contexto colonialista de desenvolvimento social. Baseado na aquisição de terras e pertencimento a essa terra por parte dos quilombolas e cabras, já que os brancos eram os donos oficialmente (SOUZA, T., 2013).

Sempre um degrau abaixo na escada da civilização, Mirandiba instiga para uma investigação que se dá na relação entre exercício de poder colonial e o saber escolar instituído, como fizeram as autoras Peters, Schnorr e Tauscheck (2014) ao entenderem um município pelo controle e posse de terras, desprezando o que diz o discurso midiático e indo a fundo na "reconstrução histórica das territorialidades, identidades, memórias, pertencimentos promovendo práticas descoloniais e interculturais no sentido de ruptura com o ciclo de reprodução das formas de dominação" (p.245).

As formas de dominação propostas pelas autoras são do campo cultural, político, econômico e epistêmico. Todas elas são amplamente massificadoras quando divulgadas pelas mídias, a proposta em reconstruir a história do Grupo Escolar Elizeu Campos sem o suporte midiático apenas confirma a necessidade de um método filosófico intercultural.

A interculturalidade está na voz, nas memórias e na resistência de acreditar "que o mundo não pode ser reduzido ao mercado" (PETERS, SCHNORR \& TAUSCHECK, 2014, p.246). Trata-se de assumir uma posição em combate ao analfabetismo biográfico da comunidade em questão e recuperar histórias e contextos plurais praticando a interculturalidade em resumo como um exercício descolonial.

Diante da formação educacional dos sujeitos mirandibenses e da interculturalidade encontrada no processo de modernização e urbanização da localidade, nos deparamos com a formação humana de um sujeito frente ao processo de globalização, econômico, tecnológico e industrial da mundialização (RÖHR, 2014).

Ao eliminar as mídias impressas como fonte de pesquisa, elimina-se, por consequência, a engrenagem que sustenta os símbolos da instauração da República no Brasil. A ausência de meios de comunicação em Mirandiba nos obriga a enfrentar aspectos filosóficos da educação do homem e seu processo de humanização. 
Embasados na diversidade cultural inerente às sociedades e suas diversas visões de mundo, buscamos nas memórias da ex-professora Valquíria Gomes Vieira, como eram entendidas e repassadas as lições das coisas no Grupo Escolar Elizeu Campos, e quais aspectos têm as consequências sofridas neste processo educacional. Para entendermos, dona

Figura 5: Dona Valquíria em entrevista.

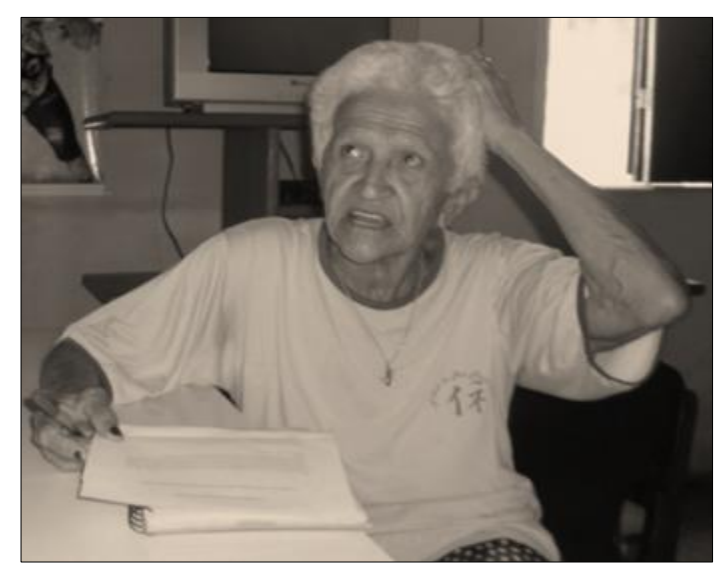

Fonte: Foto realizada pela pesquisadora.

Valquíria começa contando como foi o seu caminho de formação humana.

Eu era da roça, meus pais não tinham estudo e eu fui a primeira pessoa da família a me formar, fiz o magistério. Passei muito tempo, não sei quanto tempo, mas foram muitos anos ensinando nas fazendas. Nas roças não tinha nem sala de aula direito, os meninos tinham que levar seus banquinhos para apoiar o caderno, e sentavam no chão. Dava gosto ensinar aqueles meninos daquela época [1950-1970], não tinha esse aluno meu que não aprendesse. Eu era linha dura, mas a gente se respeitava. Só era a cartilha com assunto de português, matemática, geografia e ciências, um livro para cada ano. Quando acabava as lições da primeira cartilha eu adiantava os meninos de série, e eu fui a única professora de Mirandiba que conseguiu homogeneizar uma turma. Todo professor e professora reclamava, mas eu entendia cada um e seu jeito de aprender. Veja, os meninos da roça não aprendiam menos do que os do centro, mesmo com pouco material eu conseguia ensinar porque eu também aprendia. Sei lá, as crianças de antigamente eram mais interessadas, hoje numa turma você encontra um ou dois que querem aprender mesmo. Antigamente não, eu percebia o interesse e colocava cada um pra fazer alguma coisa, e eles queriam responsabilidade de adulto, queriam apagar o quadro, queriam ser o inspetor da semana, gostavam de vigiar uns aos outros. Ficavam sozinhos e não tinha bagunça, porque teve época que eu ensinei o primeiro e o terceiro ano de uma vez só. O que dá mais gosto de lembrar é da merenda das turmas da roça, que podia ser sete horas da manhã mas, a merenda era almoço, e aquele leite de vaca, tudo doação dos pais dos alunos, não tinha merenda da prefeitura nesse tempo. E só conseguia dar aula no centro de Mirandiba, quem passava pelas roças. Quando eu consegui dar aula só no centro no Grupo Escolar mesmo, pouco tempo depois construíram o outro Grupo. Todo 
professor e professora queria ir para o novo, era maior e mais ventilado. Lá no Grupo Elizeu não tinha inspeção, a diretora dona Lilia (Maria do Desterro Carvalho Torres) que mandava em tudo, era filha de Capitão Elizeu. Ela também era professora, antes dava aula particular (VALQUÍRIA, 2016).

Esse trecho da entrevista com Dona Valquíria resume seus métodos, de onde vinham as ordens, como era exercer a função de professora em Mirandiba na década de 1960. Fica nítido que seus métodos de ensino eram mistos ou múltiplos. Não tão somente baseado no método intuitivo, mas também com características tradicionais enraizadas na técnica da repetição como mandava as cartilhas ou livros.

Ela não guardou materiais de seu tempo de professora, mas justamente a falta desses materiais influenciou o estilo próprio de Dona Valquíria. Sua base familiar humilde e sua posição como professora era diferente de outras mulheres em mesma situação social. A maioria das professoras de Mirandiba é da família patriarcal da cidade até os dias atuais.

Voltando ao método intuitivo, consta na historiografia sobre grupos escolares que tal metodologia com o auxílio de determinados materiais pedagógicos que acompanhassem o princípio ativo das coisas, servia como educador do professor. Esta afirmação se dá pelo fato de ter ocorrido juntamente com a mudança metodológica de ensino uma mudança na forma de se fazer política em todo Brasil (RESENDE, 2002).

A ideia era de que a razão deveria colocar-se acima da fé, essa primazia positivista introduzia nos grupos escolares o cunho de modernidade, tornando retrógrado todo esforço praticado, anteriormente inclusive, o esforço da igreja (RESENDE, 2002).

Resta entender que Mirandiba não seguia os padrões educacionais de outros municípios, e que as diferenças se apresentam gritantemente. O que diferenciava a regra da prática salta aos olhos no trecho da pesquisa de Resende (2002).

Estas mudanças [de cunho político da educação] foram significativas e não ocorreram sem tensões, cujo palco foram, inicialmente, as grandes cidades. Prostitutas, mendigos, crianças abandonadas não poderiam fazer parte do cotidiano das cidades republicanas que seriam adornadas por novos procedimentos e atitudes (Ibidem. p.72).

A primeira evidência do campo das diferenças entre Mirandiba e outros municípios que receberam grupos escolares é o fato de que a cidade em questão não é uma cidade de grande porte, e por consequência de sua pequenez geográfica diante de capitais do país, prostitutas, mendigos e crianças abandonadas não existiam em grandes números, portanto, não aparecem nas memórias analisadas.

No entanto, mesmo em situação dispare, Mirandiba e o Grupo Escolar Elizeu Campos foram palco de transformações humanas, nas quais se debruçam este artigo, e tais mutações se deram interculturalmente.

[...] as inovações metodológicas da educação foram produtos e produtores de mudanças de formas de pensamento, de posturas em relação à nação e aos próprios movimentos individuais [grifo nosso], enfim, de mudanças significativas em relação a todos os aspectos da vida dos cidadãos [grifo nosso]. As inovações na educação, incluindo novos métodos de ensinoaprendizagem, entre eles, o método intuitivo, foram também instrumentos destas mudanças (RESENDE, 2002. p. 73). 
A interculturalidade está nos movimentos individuais em relação à formação do homem ou do cidadão. A ambivalência do intercultural está por sua vez no campo das igualdades e diferenças inerentes às comunidades. A diversidade das visões de mundo infectada pela indústria cultural, tende a nivelar ou igualar os sujeitos (RÖHR, 2014).

\section{Considerações finais}

A nivelação ou igualdade dos sujeitos não significa a união dos mesmos, e sem a injeção da indústria cultural em Mirandiba é possível afirmar que as diferenças e igualdades das visões de mundo dos mirandibenses foram reflexos da educação e do jogo político existente. Longe dos meios de comunicação, ficou a cargo do grupo escolar e da gestão municipal assumir a disputa ideológica.

Mirandiba sofria com um apartheid entre 1930 e 1990, a separação dos munícipes fora do grupo escolar era comum e fazia parte de uma visão de mundo autoritária (SOUZA, T., 2013). O Grupo Escolar Elizeu Campos, por sua vez, pregava uma visão de mundo conciliativa, contrária ao que regia as regras praticadas pelos coronéis, abrindo caminho de confronto na comunidade.

O esforço educativo ou pedagógico do Grupo Escolar Elizeu Campos se mostrou através das memórias forte aparelho comunitário, capaz de reunir os grupos participantes da cidade, dando a eles o acesso às forças formadoras que são incumbidas de ativar um compromisso com a realidade, dando conta da alteridade e cumprindo o objetivo central de uma comunidade.

A formação humana iniciada pela visão de mundo pedagógica alimentada pela comunidade escolar funcionou como o combustível dos mirandibenses, pois eles se apropriaram desta visão conciliativa. Alguns alunos se apropriaram de tal forma que se tornaram prefeitos. Pode-se afirmar, no entanto, que algumas visões de mundo poderiam ser consideradas egoístas.

Mas suas visões egoístas não impediram o que alguns chamam de catástrofe (RÖHR, 2014), diz-se que tal catástrofe foi sobretudo uma revolução política - moral de grande importância para os mirandibenses, quando o ex-aluno Nelson Pereira de Carvalho se apropriou de fato da visão conciliativa proposta pelo Grupo Escolar Elizeu Campos, e reuniu forças para assumir a gestão do município.

Nelson, na década de 1990, instituiu cursos técnicos e cooperativas da agricultura à Engenharia Elétrica em Mirandiba, levou mais informação à cidade, dando outro sentido a mão de obra local, utilizou-se do trabalho como ponte para humanização, legitimando o significado que o Grupo Escolar Elizeu Campos teve em sua formação humana, perpassando esse sentido para Mirandiba em seu espaço mais amplo.

O acesso à informação e a comunicação social que passou a existir em Mirandiba em 1990 é o que conclui a hipótese deste estudo, de que a falta desses mecanismos sociais, ou o monopólio midiático, influenciam de forma diferenciada a comunidade, no primeiro caso a falta de informações exila a comunidade numa espécie de ilha onde a cultura local se torna principal educadora.

Por outro lado, o monopólio midiático lança sobre a comunidade uma atmosfera cosmopolita onde se ensina que o poder de compra do cidadão é uma importante busca humana. Ambos os contextos têm seus prós e contras, mas, decididamente "a comunicação social é essencial para o desenvolvimento das capacidades humanas, para uma autonomia intelectual e para a consciência crítica diante de forças sociais arbitrárias e niveladoras" (ÉTICA..., 2017. p. 03), tendo o poder público a obrigação de promover e apoiar o diálogo a respeito das principais esferas da intelectualidade. 
Comprova-se a importância da comunicação para a educação e civilização de um povo. Do exílio cultural à globalização do modismo, necessita-se de uma rede para interligar do micro ao macro, essa rede é a comunicação presente nas mídias sociais tecnológicas e na ligação biológica humana, o uso desta ferramenta empírica modela a interação social e reconstrói as paredes de uma história.

\section{Referências}

\section{Fontes orais}

João Batista Rodrigues dos Santos. Entrevista realizada em 09 de novembro de 2016Mirandiba, Pernambuco.

Nelson Pereira de Carvalho. Entrevista realizada em 09 novembro de 2016- Mirandiba, Pernambuco.

Valquíria Gomes Vieira. Entrevista realizada em 09 novembro de 2016- Mirandiba, Pernambuco.

\section{Bibliografia}

ARAÚJO, José Carlos Souza. As instituições escolares na primeira república: ou os projetos educativos em busca de hegemonia. In: SAVIANI, Dermeval. [et al.], (orgs.) Instituições Escolares no Brasil: conceito e reconstrução histórica. Campinas, SP: Autores Associados: HISTEDBR; Sorocaba, SP: Uniso; Ponta Grossa, PR: UEPG, (2007)

BUFFA, Ester. Os estudos sobre instituições escolares: organização do espaço e propostas pedagógicas. In: SAVIANI, Dermeval. [et al.], (orgs.) Instituições Escolares no Brasil: conceito e reconstrução histórica. Campinas, SP: Autores Associados: HISTEDBR; Sorocaba, SP: Uniso; Ponta Grossa, PR: UEPG, (2007)

CASTANHO, Sérgio. Institucionalização das instituições escolares: final do império e primeira república no Brasil. In: SAVIANI, Dermeval. [ et al.], (orgs.) Instituições Escolares no Brasil: conceito e reconstrução histórica. Campinas, SP: Autores Associados: HISTEDBR; Sorocaba, SP: Uniso; Ponta Grossa, PR: UEPG, (2007)

CÓRDULA, Elisabeth. Distribuição e diversidade da caatinga no município de Mirandiba. Dissertação de Mestrado em Biologia. UFPE. 2008

COSTA, Sizenando. (1941). A Escola Rural. Rio de Janeiro: Serviço Gráfico do IBGE. INSTITUTO NACIONAL DE ESTUDOS E PESQUISAS EDUCACIONAIS. (1987). A educação nas mensagens presidenciais (1890-1986). Brasília, Mec. vol. I

EDITORIAL, Revista Filosofia Ciência e Vida - Ética na Comunicação. Ética na Mídia: os necessários debates para um paradigma ético dos meios de comunicação. Editora Escala. Edição 118. 2017

FAURE, Xavier Jean Charles. "As lideranças quilombolas em Mirandiba, PE: novos mediadores conquistando espaços nas arenas locais de poder”. Artigo. UFCG 2015. 
LEAL, Victor Nunes. "Coronelismo, enxada e voto: o município e o regime representativo no Brasil”. (2012) Edição digital disponível em: http://www.academia.edu/8401676/ Coronelismo_Enxada_e_Voto. Acessado em 06/07/2015

LUPORINI, Jussara Teresa. Instituições Escolares: Práticas. In: SAVIANI, Dermeval. [et al.], (orgs.) Instituições Escolares no Brasil: conceito e reconstrução histórica. Campinas, SP: Autores Associados: HISTEDBR; Sorocaba, SP: Uniso; Ponta Grossa, PR: UEPG, (2007)

MONARCHA, Calos. História da educação brasileira 9esboço da formação do campo). In: SAVIANI, Dermeval [et al.], (orgs.) Instituições Escolares no Brasil: conceito e reconstrução histórica. Campinas, SP: Autores Associados: HISTEDBR; Sorocaba, SP: Uniso; Ponta Grossa, PR: UEPG, (2007)

NORONHA, Maria Olinda. Historiografia das instituições escolares: Contribuição ao debate metodológico. In: SAVIANI, Dermeval. [et al.], (orgs.) Instituições Escolares no Brasil: conceito e reconstrução histórica. Campinas, SP: Autores Associados: HISTEDBR; Sorocaba, SP: Uniso; Ponta Grossa, PR: UEPG, (2007)

PAOLIELLO-OLIVEIRA, Tomas Pacheco, "Possibilidades teóricas e políticas de abordagem da questão étnica pela geografia" Artigo do Anais do XVI Encontro Nacional dos Geógrafos UFRJ. 2010

PETERS, Ana. SCHNORR, Giselle. TAUSCHECK, Neusa. Descolonização de saberes e interculturalidade: a cultura cabloca, o conflito do contestado e seus ecos nos dias atuais. 2014

PINHEIRO, Antonio Carlos Ferreira. A era das escolas rurais primárias na paraíba (1935 a 1960). - Universidade Federal da Paraíba. http://www.histedbr.fe.unicamp.br/ acer_histedbr/seminario/

PORCEL, Najar Roberto. República e Educação: as imagens arquitetônicas e jornalísticas do Grupo Escolar Barão de Monte Santo (Mococa-SP). Mestrado Educação, Sociedade, Política e Cultura UNICAMP .2007

RESENDE. Fernanda Mendes. O domínio das coisas: o método do intuitivo em Minas Gerais nas primeiras décadas Republicanas. Mestrado em Educação/ Sociedade, Cultura e Educação UFMG. 2002.

REZENDE, Antônio Muniz de. Concepção fenomenológica da educação. São Paulo: Cotez: Autores Associados, 1990. 96 p. (Coleção Polêmica do Nosso Tempo. v.38)

REZENDE, Antônio Muniz de. Concepção fenomenológica da educação. São Paulo: Cotez: Autores Associados, 1990. 96 p. (Coleção Polêmica do Nosso Tempo. v.38)

RÖHR, Ferdinand Interculturalidade e formação humana: contribuições de Martin Buber. p.123- 130 In. CARVALHO, Adalberto Dias de. Interculturalidade, educação e encontro de pessoas e povos. 2014

SANFELICE, José Luís. História das instituições escolares. In: SAVIANI, Dermeval. [et al.], (orgs.) Instituições Escolares no Brasil: conceito e reconstrução histórica. Campinas, SP: Autores Associados: HISTEDBR; Sorocaba, SP: Uniso; Ponta Grossa, PR: UEPG, (2007) 
SAVIANI, Dermeval. [et al.], (orgs.) Instituições Escolares no Brasil: conceito e reconstrução histórica. Campinas, SP: Autores Associados: HISTEDBR; Sorocaba, SP: Uniso; Ponta Grossa, PR: UEPG, (2007)

SOUZA, Rosa Fátima de. ÁVILA, Virgínia Pereira da Silva de. As disputas em torno do ensino primário rural (São Paulo, 1931-1947). Hist. Educ. [Online] Porto Alegre v. 18 n. 43 Maio/ago. 2014 p. 13-32. https://doi.org/10.1590/S2236-34592014000200002

SOUZA, Tulane Silva de. "Mirandiba 100 anos de história e política: 1912-2012". TCC em Comunicação Social - Jornalismo. Recife: Ed. Univerrsitária da UFPE, 2013.

VILLELA. Heloisa de O. S. O mestre-escola e a professora. LOPES, Eliane Marta Teixeira. FARIA FILHO, Luciano Mendes de. VEIGA, Cynthia Greive. 500 anos de educação no Brasil. Belo Horizonte: Autêntica, 2000. Coleção Historial. 